\title{
Distribution and insertion numbers of transposable elements in species of the Drosophila saltans group
}

\author{
Juliana P. de Castro, Nathalia de Setta and Claudia Marcia A. Carareto \\ UNESP, Universidade Estadual Paulista, Departamento de Biologia, São José do Rio Preto, SP, Brazil.
}

\begin{abstract}
Information about the distribution and insertion numbers of many transposable elements is restricted to few species of Drosophila, although these elements are widely distributed throughout the genus. The aim of this work was to describe the distribution and insertion numbers of four retrotransposons (copia, gypsy, micropia, I) and four transposons (hobo, mariner, Minos and Bari-1) in the saltans group of Drosophila. Our data shows that, except for mariner, all the other elements are widespread within the saltans group and show variable insertion numbers of up to 24 copies.
\end{abstract}

Key words: Drosophila, genomic insertion, saltans group, retrotransposons, transposons.

Received: March 11, 2005; Accepted: September 20, 2005.

\section{Introduction}

Transposable elements are a major component of the genomes of most species and are widespread throughout the genus Drosophila. Most of our knowledge on transposable elements in Drosophila comes from studies carried out in natural populations of Drosophila melanogaster that provided information about the dynamics of transposable elements and the forces that maintain them in genomes and populations (e.g., Montgomery et al., 1987; Charlesworth and Langley, 1989; Charlesworth et al., 1992a,b; Eanes et al., 1992; Biémont et al., 1994; Sniegowski and Charlesworth, 1994; Nuzhdin and Mackay, 1994; Pimpinelli et al., 1995; Hoogland and Biémont, 1996; Nuzhdin et al., 1997; Charlesworth et al., 1997; Vieira et al., 1998; Junakovic et al., 1998; Maside et al., 2001; Ruiz and Carareto, 2003). Although it is well established that transposable elements have played a major role in evolution and may still be useful in maintaining the genetic variability of natural populations, the nature of the evolutionary forces that control their abundance are yet poorly understood. However, the sequence of $D$. melanogaster released by the Drosophila Genome Project (Celniker et al., 2003 Release 3) introduced a new perspective to understand the nature, number and location of the $D$. melanogaster transposable elements.

In brief, the published data have shown that the Drosophila euchromatic genome seems to be composed of

Send correspondence to Claudia M.A. Carareto. UNESP, Universidade Estadual Paulista, Departamento de Biologia, Rua Cristóvão Colombo 2265, 15054-000 São José do Rio Preto, SP, Brazil. E-mail: carareto@ibilce.unesp.br. a mixture of active and of ancient relic transposable elements, that their distribution along the chromosome results from natural selection and that the long terminal repeat (LTR) and non-LTR retrotransposons possess fewer divergent elements than transposons (Lerat et al., 2003). The elements are grouped into 96 families and can occur as a single copy or as many as 146 copies, with more than two-thirds of sequences being only partial (Kaminker et al., 2002). The data also show that transposable elements are not randomly distributed along the chromosomes but seem to be associated with reduced recombination rates (Bartolomé et al., 2002; Rizzon et al., 2002), however, this relationship depends on specific characteristics of the chromosomes, the transposable elements themselves and the species (Rizzon et al., 2002). These studies shed some light on the nature of the mechanisms involved in the control of transposable element abundance. However, comparative studies using species other than D. melanogaster are needed for a broad understanding of the evolutionary dynamics of Drosophila transposable elements.

Although a significant amount of data referring to transposable elements in D. melanogaster and other Drosophila species is available, much information is still missing about the occurrence and genomic distribution of many transposable elements in many Drosophila species. Two analyses (Martin et al., 1983; Stacey et al., 1986) and one review (Biémont and Cizeron, 1999) summarize the main knowledge accumulated so far regarding transposable elements in Drosophila. The first two studies concerned the elements copia, 412 and 297 in 32 species (Martin et al., 1983 ) and the elements $P, I$, gypsy, copia and $F$ in 34 spe- 
cies (Stacey et al., 1986), while the review includes data of individual studies on 228 Drosophila species and 43 transposable elements including copia, gypsy, $I$ and $P$ elements. These analyses showed that many transposable elements are present in many Drosophila species, but there are some major differences among them. For example, copia, 412 and gypsy have been detected in almost all species (Martin et al, 1983; Stacey et al., 1986), while the I retrotransposon is restricted to the melanogaster subgroup (de Frutos et al., 1992). In the saltans group, for example, only the $P$ element has been studied in species of the five subgroups.

For Drosophila species in which the complete genomic DNA sequence is not available sampling of laboratory and natural strains for transposable elements by in situ hybridization and Southern blot analyses is still the best way to characterize their transposable elements and understand the evolutionary dynamics of these elements. The aim of our research was to provide more information on transposable element distribution and copy number in the Drosophila saltans group by describing the distribution and copy number of the copia, gypsy, micropia and I retrotransposons (class I elements) and the hobo, mariner, Minos and Bari-1 transposons (class II elements) in members of the Drosophila saltans group of fruitflys.

\section{Materials and Methods}

\section{Fruitfly stocks}

All the Drosophila species and strains used in the present study are listed in Table 1 and were derived from a single, randomly selected female from a mass culture. Positive controls were D. melanogaster (Harwich strain) and
Drosophila mauritiana (Tucson Stock Center: 140210241.1).

\section{PCR and Southern blot analyses}

For each Drosophila strain, total genomic DNA was prepared from 25-30 adult flies according to the method of Jowett (1986) and PCR reactions performed in $25 \mathrm{~mL}$ volumes using approximately $200 \mathrm{ng}$ of template DNA, 100 $\mathrm{mM}$ of each primer, $200 \mathrm{mM}$ of dNTPs, $1.5 \mathrm{mM}$ of $\mathrm{MgCl}_{2}$, $5 \%(\mathrm{v} / \mathrm{v})$ of DMSO and 1 unit of Taq DNA Polymerase (GIBCO-BRL) in 1x Polymerase buffer. For amplification, we used an initial denaturation step of $5 \mathrm{~min}$ at $94{ }^{\circ} \mathrm{C}$ and an additional extension step of $10 \mathrm{~min}$ at $72{ }^{\circ} \mathrm{C}$ after the last cycle were performed. The amplification parameters varied as follows depending on the element: Minos $=29$ cycles consisting of 1 min denaturation at $94{ }^{\circ} \mathrm{C}, 1 \mathrm{~min}$ annealing at $54^{\circ} \mathrm{C}$ and $1 \mathrm{~min}$ extension at $72^{\circ} \mathrm{C}$; micropia $=40$ cycles consisting of 1 min denaturation at $95^{\circ} \mathrm{C}, 1 \mathrm{~min}$ annealing at $52{ }^{\circ} \mathrm{C}$ and 2 min extension at $72{ }^{\circ} \mathrm{C}$; Bari- $1=35$ cycles consisting of $1 \mathrm{~min}$ denaturation at $95^{\circ} \mathrm{C}, 1 \mathrm{~min}$ annealing at $60{ }^{\circ} \mathrm{C}$ and $5 \mathrm{~min}$ extension at $72{ }^{\circ} \mathrm{C}$; gypsy $=40$ cycles consisting of $30 \mathrm{~s}$ denaturation at $94{ }^{\circ} \mathrm{C}, 30 \mathrm{~s}$ annealing at $55^{\circ} \mathrm{C}$ and $30 \mathrm{~s}$ extension at $72{ }^{\circ} \mathrm{C}$; hobo, $\mathrm{I}$ and copia $=30$ cycles consisting of $30 \mathrm{~s}$ denaturation at $95^{\circ} \mathrm{C}, 30 \mathrm{~s}$ annealing at $58{ }^{\circ} \mathrm{C}$ and 1 min extension at $72{ }^{\circ} \mathrm{C}$. Despite trying various combinations of parameters mariner did not amplify by PCR.

To estimate the overall amount of each transposable element in the analyzed species using Southern blot, $10 \mathrm{mg}$ of genomic DNA from each strain was digested with appropriate restriction enzymes (Table 2), submitted to electrophoresis on $0.8 \%(\mathrm{w} / \mathrm{v})$ agarose gels and transferred to Hybond $\mathrm{N}+$ nylon membranes (Amersham Biosciences).

Table 1 - Details of the Drosophila saltans species and strains used in this study.

\begin{tabular}{|c|c|c|}
\hline Drosophila subgroup, species and strain & Location and year collected & Stock center number ${ }^{1}$ \\
\hline \multicolumn{3}{|l|}{ cordata } \\
\hline D. neocordata NEO strain & Minas Gerais, Brazil 1959 & (SC14041-0831.0) \\
\hline \multicolumn{3}{|l|}{ elliptica } \\
\hline D. emarginata EVC strain & Vera Cruz, Mexico 1962 & (SC14042-0841.6) \\
\hline \multicolumn{3}{|l|}{ parasaltans } \\
\hline D. parasaltans PAT strain & Tapuruquara, Brazil 1962 & Collected by H.Bicudo ${ }^{2}$ \\
\hline D. subsaltans SUB strain & Belém, Brazil 1959 & $(\mathrm{SC}-14044-0872.0)$ \\
\hline \multicolumn{3}{|l|}{ sturtevanti } \\
\hline D. milleri MEY strain & El Yunque, Puerto Rico 1962 & $(\mathrm{SC}-14043-0861.0)$ \\
\hline D. dacunhai DAP strain & Pentionville, Haiti 1962 & $(\mathrm{SC}-14043-0854.0)$ \\
\hline D. sturtevanti SMX strain & Matlapa, Mexico 1998 & Collected by J.Silva ${ }^{3}$ \\
\hline \multicolumn{3}{|l|}{ saltans } \\
\hline D. austrosaltans API strain & Pirassununga, Brazil 1959 & $(\mathrm{SC}-14045-0881.0)$ \\
\hline D. saltans $\mathrm{SAC}$ strain & Chilpancingo, Mexico 1962 & Collected by H. Bicudo ${ }^{2}$ \\
\hline D. prosaltans $\mathrm{PTT}$ strain & Sangre Grande, Trinidad Tobago 1962 & Collected by H. Bicudo ${ }^{2}$ \\
\hline
\end{tabular}

${ }^{1}$ Tucson Stock Center, University of Arizona, Tucson, AZ, USA. ${ }^{2}$ UNESP-São José do Rio Preto, SP, Brazil. ${ }^{3}$ University of Arizona, Tucson, AZ, USA. 
Table 2 - Primers, probes and restriction enzymes used for the copy number detection of each transposable element in saltans group Drosophila species.

\begin{tabular}{|c|c|c|c|c|}
\hline Element plasmid $^{1}$ & Primers & Annealing regions & Probe extension $(b p)^{2}$ & Restriction enzymes \\
\hline copia & LTR-5'CTATTCAACCTACAA AAATAACG3' & 33 to 56 & \multirow[t]{2}{*}{439} & \multirow[t]{2}{*}{ Xho I } \\
\hline $\mathrm{p} 77 \mathrm{E} 4$ & PCS-5'ATTACGTTTAGCCTTGTCCAT3' & 451 to 472 & & \\
\hline gypsy & GM003-5'GTACTGAACATTATCAGAATC3' & 2155 to 2176 & \multirow[t]{2}{*}{542} & \multirow[t]{2}{*}{ Bam H1 } \\
\hline pGGHS & GM004-5'TCTAAGGAGTCCTCTGCAAGG3' & 2676 to 2697 & & \\
\hline micropia & 2813-5'TTAACTCCTAGAGTTCATCGCTGG3' & 2813 to 2839 & \multirow[t]{2}{*}{387} & \multirow[t]{2}{*}{ Bam HI } \\
\hline $\mathrm{dhMiF}_{2}$ & 2814-5'CATGTACCTGGTTAACTACTGACC3' & 3174 to 3198 & & \\
\hline I & IF-5'CTCACACTCTGCTCTCCAAT3' & 2178 to 2198 & \multirow[t]{2}{*}{635} & \multirow[t]{2}{*}{ Eco RI } \\
\hline pI407 & IR-5'TTGTGCGAATATGTTTAG CAA3' & 2792 to 2813 & & \\
\hline hobo & HA-5'CACCTCCAATTTATCCCGCC 3 ' & 651 to 671 & \multirow[t]{2}{*}{963} & \multirow[t]{2}{*}{ Bam H1 } \\
\hline $\mathrm{pHX} 4$ & HB-5'GGATGGCAATACGAAGC3' & 1597 to 1614 & & \\
\hline mariner & MAR1-5’CCAGGTGTACAAGTAGG3' & 1 to 15 & 800 & \multirow[t]{2}{*}{ Pst I } \\
\hline Mos1 & MAR1286-5'GTATGAACATGTTGGACT3' & 1286 to 1300 & NheI/PvuII * & \\
\hline Minos & M5-5’TATCGATAATTCACAATACAGCATG3’' & 1 to 26 & \multirow[t]{2}{*}{1068} & \multirow[t]{2}{*}{ Xho I } \\
\hline pBCKSP & M3-5'ATCAAGCTTGAATTGTGTAACGTCGCC3' & 1054 to 1068 & & \\
\hline Bari-1 & 453-5'ATTCGTCGCAGGCTAAAAGA3' & \multirow[t]{2}{*}{453 to 1196} & \multirow[t]{2}{*}{703} & \multirow[t]{2}{*}{ Eco RI } \\
\hline p28/47D & 1196-5'TTGTAACACCACCTTTGGCA3' & & & \\
\hline
\end{tabular}

${ }^{1}$ Plasmid source: p77E4 and pHX4 = E. Loreto (UFSM, Santa Maria, RS, Brazil); pGGHS = D. Dorsett, Memorial Sloan-Kettering Cancer Center, USA; dhMiF2 = D.H Lankenau, University of Heidelberg, Heidelberg, Germany; pI407 = A. Bucheton, CNRS, Montpellier, France; Mos1 = D.L. Hartl, Harvard University, Cambridge, MA; pBCKSP = B. Arcà, University of Roma 'La Sapienza', Roma, Italy; and p28/47D = R. Caizzi, University of Bari, Bari, Italy. ${ }^{2}$ TE sequences inserted into plasmids were derived from: D. melanogaster (p77E4, pGGHS, pI407, pHX4 and p28/47); D. mauritiana (Mos1); D. mojavensis (pBCKSP); and D. hydei $\left(\mathrm{dhMiF}_{2}\right) .{ }^{*}$ Fragment.

The probes used were sequences amplified from plasmids containing sequences of each transposable element (Table 2). For hybridization and detection we used the chemioluminescent hybridization system Gene Images (Amersham Biosciences) at high stringency $\left(58^{\circ} \mathrm{C}-60^{\circ} \mathrm{C}\right)$ according to the manufacturer's instructions. Our analysis was based on the full transposable element sequences as described for D. melanogaster or the species from which a specific element was first sequenced (copia: X02599; gypsy: M12927; micropia: X13304; I: X78904; hobo: M69216, mariner: X78906; Minos: X61695 and Bari-1: $\mathrm{X} 67681$ ). In order to obtain a single band per element insertion, restriction enzymes that do not cut within the element sequence were selected for digestion of the genomic DNA (Table 2) so that different fragment lengths are assumed as product of variable genomic insertions.

\section{Results and Discussion}

The status of the saltans group species in relation to the presence of the retrotransposable elements copia, gypsy, micropia, $I$ and the transposable elements hobo, mariner, Minos and Bari-1 is presented in Table 3 where all the available data on these elements is presented along with the data produced in the study described in this paper. The distribution of sequences homologous to these elements showed strong to weak or no hybridization signals among the saltans group species (Figures 1 and 2). All analyses were repeated several times but some of the blots still showed unsatisfactory hybridization signals (e.g. the $I$ and mariner elements whose blots are not shown in the figures), underlining the difficulty in obtaining good hybridizations using probes for D. melanogaster elements. However, PCR amplifications using specific primers and the blotting of amplified sequences with the primers and probes described in Table 2 ensured that the weak signals were not due to nonspecific hybridization. The mariner transposon produced no PCR amplification products.

Hybridization to the micropia, copia, gypsy and I retrotransposon homologous sequences were observed in all species (Figure 1). Although micropia sequences have previously been described for the saltans group (Almeida et al., 2001; Lankenau, 1993) the copy number has not previously been estimated. Despite the weak signals for copia and $I$ elements (obtained after two hours of exposure, as compared with 30 minutes for the other sequences), our results indicate a broad distribution of both these retrotransposons among species of the saltans group. The same difficulty regarding copia hybridization blots in obscura group species was encountered by de Frutos et al. (1992). Previous reports have provided conflicting data regarding the distribution of copia homologous sequences in other Drosophila species. Brookfield et al. (1984) suggested that copia sequences are restricted to D. melanogaster and related species but a broader distribution within the Sophophora subgenus was subsequently observed by Stacey et al. (1986), who also reported that gypsy is widely distributed among Sophophoran species including the drosophilids $D$. emarginata, $D$. sturtevanti, $D$. austrosaltans and $D$. prosaltans but not $D$. neocordata. Our results support the hypothesis regarding the wide distribution of the retrotransposon gypsy in drosophilids and extend its presence to representatives of the five subgroups of the 
Table 3 - Distribution of transposable elements in species of the saltans group.

\begin{tabular}{|c|c|c|c|c|c|c|c|c|c|c|c|c|c|c|c|c|}
\hline \multirow{4}{*}{$\begin{array}{l}\text { Drosophila subgroup } \\
\text { and species }\end{array}$} & \multicolumn{16}{|c|}{ Presence $(+)$ or absence $(-)$ of the element as determined by Southern blotting } \\
\hline & \multicolumn{8}{|c|}{ Retrotransposons } & \multicolumn{8}{|c|}{ Transposons } \\
\hline & \multicolumn{2}{|c|}{ copia } & \multicolumn{2}{|c|}{ gypsy } & \multicolumn{2}{|c|}{ micropia } & \multicolumn{2}{|c|}{$I$} & \multicolumn{2}{|c|}{ hobo } & \multicolumn{2}{|c|}{ mariner } & \multicolumn{2}{|c|}{ Minos } & \multicolumn{2}{|c|}{ Bari-1 } \\
\hline & A & * & $\mathrm{B}$ & $*$ & $\mathrm{C}$ & $*$ & $\mathrm{D}$ & * & $\mathrm{E}$ & * & $\mathrm{F}$ & $*$ & G & * & $\mathrm{H}$ & * \\
\hline \multicolumn{17}{|l|}{ cordata } \\
\hline D. cordata & + & & - & & & & - & & & & & & & & & \\
\hline D. neocordata & & + & - & + & + & + & - & + & - & + & - & + & & + & + & + \\
\hline \multicolumn{17}{|l|}{ elliptica } \\
\hline D. elliptica & + & & + & & & & - & & & & & & & & & \\
\hline D. emarginata & & + & + & + & + & + & - & + & - & + & & + & & + & + & + \\
\hline D. neoelliptica & & & & & & & & & - & & & & & & & \\
\hline \multicolumn{17}{|l|}{ parasaltans } \\
\hline D. parasaltans & & + & & + & + & + & & + & & + & & + & & + & & + \\
\hline D. subsaltans & & + & & + & + & + & & + & & + & & + & & + & + & + \\
\hline \multicolumn{17}{|l|}{ sturtevanti } \\
\hline D. sturtevanti & + & + & + & + & + & + & + & + & - & + & - & - & & + & + & + \\
\hline D. milleri & & + & & + & + & + & & + & - & + & & + & & + & & + \\
\hline D. dacunhai & & + & & + & + & + & & + & & + & & - & & + & & + \\
\hline \multicolumn{17}{|l|}{ saltans } \\
\hline D. saltans & + & + & + & + & + & + & & + & - & + & - & - & + & + & + & + \\
\hline D. lusaltans & & & & & & & & & - & & & & & & + & \\
\hline D. prosaltans & + & + & + & + & + & + & - & + & - & + & & - & & + & & + \\
\hline D. austrosaltans & + & + & + & + & + & + & - & + & - & + & & + & & + & & + \\
\hline
\end{tabular}

References: A = Jordan and McDonald (1998), Martin et al. (1983), Stacey et al. (1986); B = Stacey et al. (1986); C = Almeida et al. (2001), Lankenau (1993); D = Bucheton et al. (1986), Stacey et al. (1986); $\mathrm{E}=$ Daniels et al. (1990); F = Brunet et al. (1994), Capy et al. (1992), Maruyama and Hartl (1991); G = Arcà Band Savakis (2000); and H = Moschetti et al. (1998). *Data produced in this study using the Southern blotting method.
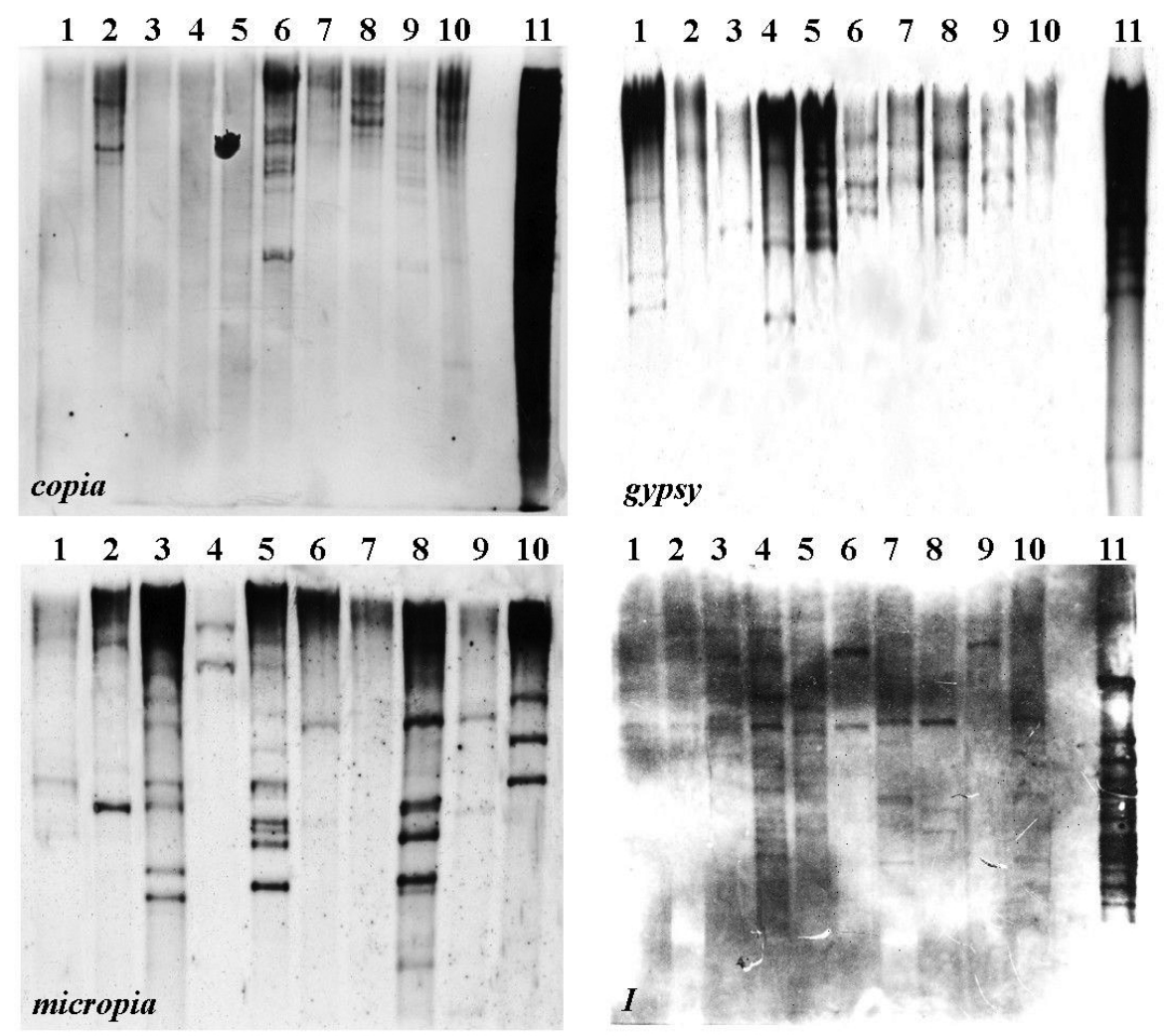

Figure 1 - Southern blot analysis of the retrotransposons copia, gypsy, micropia and $I$ in D. neocordata (1); D. emarginata (2); D. parasaltans (3); D. subsaltans (4); D. milleri (5); D. dacunhai (6); D. sturtevanti (7); D. austrosaltans (8); D. saltans (9); D. prosaltans (10) and D. melanogaster (11). 

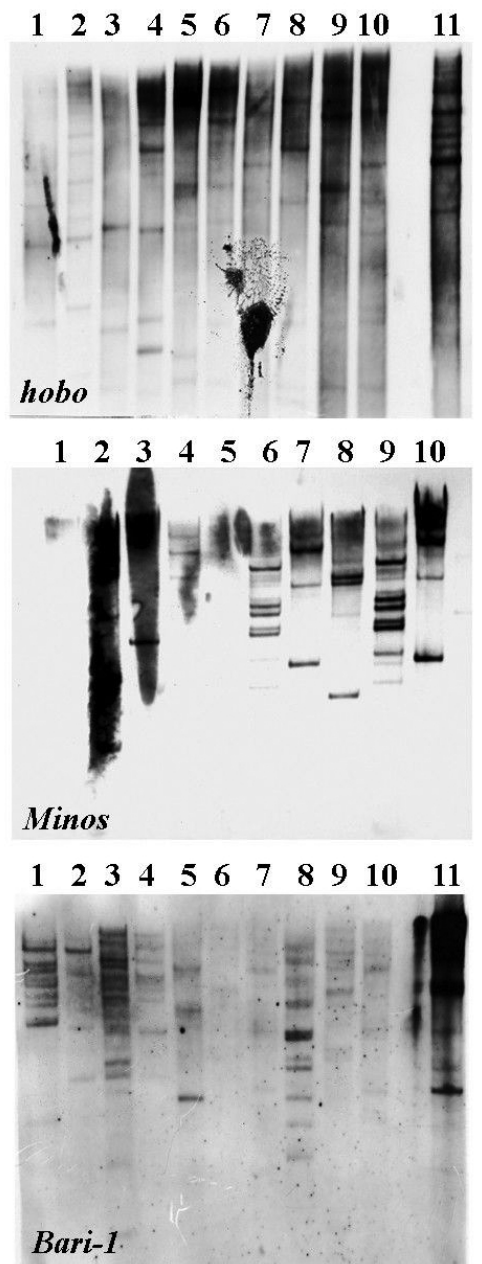

Figure 2 - Southern blot analysis of the transposons hobo, Minos and Bari-1 in D. neocordata (1); D. emarginata (2); D. parasaltans (3); D. subsaltans (4); D. milleri (5);D. dacunhai (6);D. sturtevanti (7);D. austrosaltans (8); D. saltans (9); D. prosaltans (10) and D. melanogaster (11).

saltans group, including D. neocordata. The fact that gypsy has been considered a retrovirus (Pélisson, 1994; Song et al., 1994) may explain its wide distribution. The wide distribution of the $I$ element in the saltans group does not agree with the results reported by Stacey et al. (1986), who found $I$ homologous sequences only in members of the melanogaster group, but partially agrees with Bucheton et al. (1986) who described a more widespread distribution (including $D$. sturtevanti) for this element. These inconsistent results could be accounted for by differences in the stringency conditions used by different investigators.

The distribution of transposons also conflicted with data previously reported by other investigators. With exception of mariner, for which only a few signals were observed by us in some species after the longer exposure time (three hours), we found that the other DNA elements were widely distributed in the saltans group (Figure 2). Daniels et al. (1990) carried out a wide distribution screening of hobo transposable elements in the genus Drosophila and found homologous sequences only in the melanogaster group, with Loreto et al. (1998) subsequently reporting the presence of hobo homologous sequences in $D$. willistoni. Our results extend the presence of hobo homologous sequences to the saltans group. Previous surveys have reported the absence of hybridization signals for mariner elements in the saltans group (Brunet et al., 1994) and outside the melanogaster species group (Maruyama and Hartl, 1991). For our part, we found no sequences homologous to mariner in the drosophilids $D$. dacunhai, $D$. sturtevanti, $D$. saltans and $D$. prosaltans, and only faint mariner hybridization signals in the other species investigated by us. However, this does not mean that this element is absent from these species but could simply reflect a high level of divergence between mariner elements in different species. This proposal is supported by the difficulty of hybridization between the saltans group sequences and the D. mauritiana probe. The Minos (Arcà and Savakis, 2000; Almeida and Carareto, 2005) and Bari-1 (Moschetti et al., 1998) sequences have been reported in some species of the saltans group, and our study shows that these sequences are also present in representatives of the five subgroups of the saltans group.

For the retrotransposons studied by us the copy number varied between two for the micropia element in $D$. dacunhai and 24 for the $I$ element in Drosophila parasaltans, while for transposons the copy number varied from two for the Minos element in Drosophila milleri and 15 for Bari-1 in D. parasaltans. Except for the $I$ element, the mean copy number was seven to nine different insertions per species (Table 4). However, the copy numbers were very variable among different species, probably due to drift due to the fact that the strains studied had been maintained in the laboratory for a long time.

For high copy number transposable element families Southern blotting, as compared to in situ hybridization, is known to underestimate the abundance of transposable elements, although for intermediate and low copy number families the abundance estimates produced by these two techniques show good agreement (Maside et al., 2001). Since our results showed intermediate and low copy numbers, we assumed that our methodology was appropriate for estimating the copy number of the saltans group transposable elements investigated. However, we should point out that the saltans species transposable element sequences homologous to most of the $D$. melanogaster elements studied did not, in general, show close sequence similarity to their homologues since the hybridization signals generated were not very strong, although it is still possible to hypothesize that all eight elements studied in this work were present in the ancestral saltans group.

Except for occasional examples of lateral transfer between species of the saltans and repleta groups (Almeida and Carareto, 2005) and based on the transposable element life cycle (Kaplan et al., 1985; Pinsker et al., 2001) it is to be expected that most of the transposable element se- 
Table 4 - Number of insertions (copy number) of each transposable element found in saltans group species.

\begin{tabular}{|c|c|c|c|c|c|c|c|}
\hline \multirow[b]{3}{*}{ Saltans group Drosophila species } & \multicolumn{7}{|c|}{ Copy number } \\
\hline & \multicolumn{4}{|c|}{ Retrotransposons } & \multicolumn{3}{|c|}{ Transposons } \\
\hline & copia & gypsy & micropia & $I$ & hobo & Minos & Bari-1 \\
\hline D. neocordata & 3 & 10 & 7 & 10 & 8 & 5 & 10 \\
\hline D. emarginata & 5 & 7 & 9 & 14 & 12 & 9 & 6 \\
\hline D. parasaltans & 5 & 6 & 14 & 24 & 8 & 4 & 15 \\
\hline D. subsaltans & 8 & 9 & 2 & 19 & 11 & 5 & 8 \\
\hline D. milleri & 13 & 10 & 12 & 17 & 11 & 2 & 5 \\
\hline D. dacunhai & 12 & 8 & 2 & 7 & 7 & 14 & 5 \\
\hline D. sturtevanti & 6 & 9 & 4 & 15 & 8 & 5 & 7 \\
\hline D. austrosaltans & 9 & 9 & 12 & 5 & 7 & 8 & 12 \\
\hline D. saltans & 10 & 7 & 4 & 13 & 10 & 13 & 9 \\
\hline D. prosaltans & 9 & 7 & 6 & 16 & 11 & 6 & 7 \\
\hline Mean number of insertions $\pm \mathrm{SD}^{1}$ & $8.0 \pm 3.2$ & $8.2 \pm 1.4$ & $7.2 \pm 4.4$ & $14.0 \pm 5.6$ & $9.3 \pm 1.9$ & $7.1 \pm 3.9$ & $8.5 \pm 3.2$ \\
\hline
\end{tabular}

${ }^{1}$ Standard deviation.

quences detected in our study are highly divergent compared to those found in D. melanogaster, since species from the melanogaster and saltans/willistoni groups, as well as species belonging to the subgenus Drosophila (Drosophila hydei and Drosophila mojavensis) and Sophophora (saltans species), are phylogenetically separated by about 40 million years (Russo et al., 1995).

Given the possibility of copy number underestimation by Southern blot and the high divergence between probes generated from transposable element sequences of species outside the saltans group our negative results should not be taken as definitive because it is known that the more divergent the sequence the more difficult is to detect using canonical sequences as a probe. Our study indicates the need for more complete information about the occurrence and molecular characteristics of transposable elements among different Drosophila species groups in order to understand the evolutionary history of these and other transposable elements.

\section{Acknowledgements}

This investigation was supported by the Brazilian agencies FAPESP (Grants n. 95/7192-2, 98/08734-1, 00/11313-0 and a fellowship to J.P.C.) and CNPq.

\section{References}

Almeida LM and Carareto CMA (2005) Multiple events of horizontal transfer of the Minos transposable element between Drosophila species. Mol Phyl Evol 35:583-594.

Almeida LM, Castro JP and Carareto CMA (2001) Micropia transposable element occurrence in Drosophila species of the saltans group. Dros Inf Serv 84:114-117.

Arcà B and Savakis C (2000) Distribution of the transposable element Minos in the genus Drosophila. Genetica 108:263-267.

Bartolomé C, Maside X and Charlesworth B (2002) On the abundance and distribution of transposable elements in the ge- nome of Drosophila melanogaster. Mol Biol Evol 19:926937.

Biémont C and Cizeron G (1999) Distribution of transposable elements in Drosophila species. Genetica 105:43-62.

Biémont C, Lemeunier F, Garcia Guerreiro MP, Brookfield JF, Gautier C, Aulard S and Pasyukova EG (1994) Population dynamics of the copia, $m d g 1, m d g 3$, gypsy, and $P$ transposable elements in a natural population of Drosophila melanogaster. Genet Res 63:197-212.

Brookfield JJY, Montgomery E and Langley CH (1984) Apparent absence of transposable elements related to $P$ elements of $D$. melanogaster in other species of Drosophila. Nature 310:330-332.

Brunet F, Godin F, David JR and Capy P (1994) The mariner transposable element in the Drosophilidae family. Heredity 73:377-385.

Bucheton A, Simonelig M., Vaury C and Crozatier M (1986) Sequences similar to the I transposable element involved in I-R hybrid dysgenesis in D. melanogaster occur in other Drosophila species. Nature 322:650-652.

Capy P, David JR and Hartl DL (1992) Evolution of the transposable element mariner in the Drosophila melanogaster species group. Genetica 86:37-46.

Celniker SE, Wheeler DA, Kronmiller B, Carlson JW, Halpern A, Patel S, Adams M, Champe M, Dugan SP, Frise E, Hodgson A, George RA, Hoskins RA, Laverty T, Muzny DM, Nelson CR, Pacleb JM, Park S, Pfeiffer BD, Richards S, Sodergren EJ, Svirskas R, Tabor PE, Wan K, Stapleton M, Sutton GG, Venter C, Weinstock G, Scherer SE, Myers EW, Gibbs RA and Rubin GM (2003) Finishing a whole-genome shotgun: Release 3 of the Drosophila melanogaster euchromatic genome sequence. Genome Biol 3:RESEARCH0079.

Charlesworth B and Langley CH (1989) The population genetics of Drosophila transposable elements. Annu Rev Genet 23:251-87.

Charlesworth B, Lapid A and Canada D (1992a) The distribution of transposable elements within and between chromosomes in a population of Drosophila melanogaster. I. Element frequencies and distribution. Genet Res 60:103-114.

Charlesworth B, Lapid A and Canada D (1992b) The distribution of transposable elements within and between chromosomes 
in a population of Drosophila melanogaster. II. Inferences on the nature of selection against elements. Genet Res 60:115-130.

Charlesworth B, Langley CH and Sniegowski PD (1997) Transposable element distributions in Drosophila. Genetics 147:1993-1995.

Eanes WF, Wesley C and Charlesworth B (1992) Accumulation of $P$ elements in minority inversions in natural populations of Drosophila melanogaster. Genet Res 59:1-9.

Daniels SB, Chovinick A and Boussy IA (1990) Distribution of hobo transposable elements in the genus Drosophila. Mol Biol Evol 7:589-606.

de Frutos R, Peterson KR and Kidwell MG (1992) Distribution of Drosophila melanogaster transposable element sequences in species of the obscura group. Chromosoma 101:293-300.

Hoogland C and Biémont C (1996) Chromosomal distribution of transposable elements in Drosophila melanogaster: Test of the ectopic recombination model for maintenance of insertion site number. Genetics 144:197-204.

Jordan IK and McDonald JF (1998) Evolution of the copia retrotransposon in the Drosophila melanogaster species subgroup. Mol Biol Evol 15:1160-1171.

Jowett T (1986) Preparation of nucleic acids. In: Roberts DB (ed) Drosophila: A Practical Approach. IRL Press, Oxford, pp 275-277.

Junakovic N, Terrinoni A, Di Franco C, Vieira C and Loevenbruck C (1998) Accumulation of transposable elements in the heterochromatin and on the $\mathrm{Y}$ chromosome of Drosophila simulans and Drosophila melanogaster. J Mol Evol 46:661-668.

Kaminker JS, Bergman CM, Kronmiller B, Carlson J, Svirskas R, Patel S, Frise E, Wheeler DA, Lewis SE, Rubin GM, Ashburner M and Celniker SE (2002) The transposable elements of the Drosophila melanogaster euchromatin: A genomics perspective. Genome Biol 2002:RESEARCH0084.

Kaplan N, Darden T and Langley C (1985) Evolution and extinction of transposable elements in Mendelian populations. Genetics 109:459-480.

Lankenau DH (1993) The retrotransposon family micropia in Drosophila species. In: McDonald JF (ed) Transposable Elements and Evolution. Kluwer Academic Publisher, Dordrecht, pp. 232-241.

Lerat E, Rizzon C and Biémont C (2003) Sequence divergence within transposable element families in the Drosophila melanogaster genome. Genome Res 13:1889-1896.

Loreto ELS, Basso da Silva L, Zaha A and Valente VLS (1998) Distribution of transposable elements in neotropical species of Drosophila. Genetica 101:153-165.

Martin G, Wiernasz D and Schedl P (1983) Evolution of Drosophila repetitive-dispersed DNA. J Mol Evol 19:203213.

Maruyama K and Hartl DL (1991) Evolution of the transposable element mariner in Drosophila species. Genetics 128:31929.

Maside X, Bartolome C, Assimacopoulos S and Charlesworth B (2001) Rates of movement and distribution of transposable elements in Drosophila melanogaster: In situ hybridization vs. Southern blotting data. Genet Res 78:121-136.

Montgomery E, Charlesworth B and Langley CH (1987) A test for the role of natural selection in the stabilization of transposable element copy number in a population of Drosophila melanogaster. Genet Res 49:31-41.

Moschetti R, Caggese C, Barsanti P and Caizzi R (1998) Intraand interspecies variation among Bari-1 elements of the melanogaster species group. Genetics 150:239-250.

Nuzhdin SV and Mackay TF (1994) Direct determination of retrotransposon transposition rates in Drosophila melanogaster. Genet Res 63:139-144.

Nuzhdin SV, Pasyukova EG and Mackay TF (1997) Accumulation of transposable elements in laboratory lines of Drosophila melanogaster. Genetica 100:167-75.

Pélisson A, Song SU, Prud'homme N, Smith PA, Bucheton A and Corces VG (1994) Gyspy transposition correlates with the production of a retroviral envelope-like protein under the tissue-specific control of the Drosophila flamenco gene. EMBO J 13:4401-4411.

Pimpinelli S, Berloco M, Fanti L, Dimitri P, Bonaccorsi S, Marchetti E, Caizzi R, Caggese C and Gatti M (1995) Transposable elements are stable structural components of Drosophila melanogaster heterochromatin. Proc Natl Acad Sci USA 92:3804-3808.

Pinsker W, Haring E, Hagemann S and Miller WJ (2001) The evolutionary life history of $P$ transposons: From horizontal invaders to domesticated neogenes. Chromosoma 110:148-158.

Rizzon C, Marais G, Gouy M and Biémont C (2002) Recombination rate and the distribution of transposable elements in the Drosophila melanogaster genome. Genome Res 12:400407.

Ruiz MT and Carareto CM (2003) Copy number of P elements, $\mathrm{KP} /$ full-sized $\mathrm{P}$ element ratio and their relationships with environmental factors in Brazilian Drosophila melanogaster populations. Heredity 91:570-576.

Russo CA, Takezaki N and Nei M (1995) Molecular phylogeny and divergence times of drosophilid species. Mol Biol Evol 12:391-404

Sniegowski PD and Charlesworth B (1994) Transposable element numbers in cosmopolitan inversions from a natural population of Drosophila melanogaster. Genetics 137:815-827.

Song SU, Gerasimova T, Kurkulos M, Boeke JD and Corces VG (1994) An env-like protein encoded by a Drosophila retroelement: Evidence that gypsy is an infectious retrovirus. Genes Dev 8:2046-2057.

Stacey SN, Lansman RA, Brock HW and Grigliatti TA (1986) Distribution and conservation of mobile elements in the genus Drosophila. Mol Biol Evol 3:522-534.

Vieira C, Aubry P, Lepetit D and Biémont C (1998) A temperature cline in copy number for 412 but not roo/B104 retrotransposons in populations of Drosophila simulans. Proc R Soc Lond B Biol Sci 265:1161-1165.

Editor: Fábio de Melo Sene 